\title{
OAREL
}
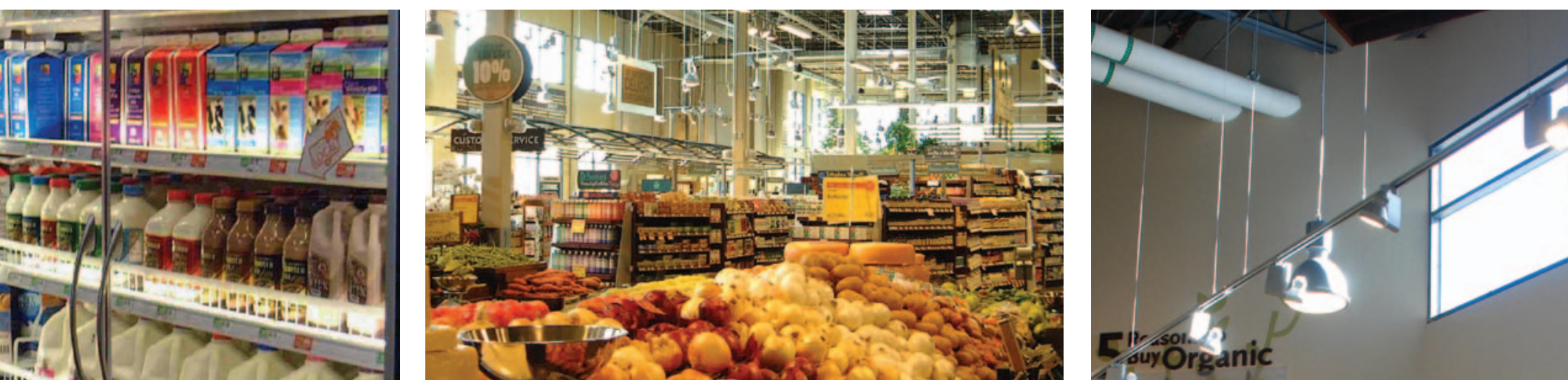

\section{THINKING LIKE A WHOLE BUILDING: A WHOLE FOODS MARKET NEW CONSTRUCTION CASE STUDY}

Michael Deru, Eric Bonnema, lan Doebber, Adam Hirsch, Maureen Mclntyre, Jennifer Scheib

NREL is a national laboratory of the U.S. Department of Energy, Office of Energy Efficiency and Renewable Energy, operated by the Alliance for Sustainable Energy, LLC. 


\section{Acknowledgments}

The authors would like to thank the U.S. Department of Energy Building Technologies Program. This document was prepared by the Commercial Buildings Group of the National Renewable Energy Laboratory (NREL) Electricity, Resources, and Buildings System Integration Center as Deliverable FY11-CBP-01 under Task BEC7.1101 in the Commercial Buildings Statement of Work.

We extend our thanks to their NREL colleagues Larry Brackney and Daniel Studer for conducting formal internal reviews of this document, to Stefanie Woodward for editing assistance, and to Marjorie Schott and Stacy Buchanan for graphic design.

All photographs contained herein were taken with the permission of Whole Foods Market.

"Whole Foods Market" is a registered trademark of Whole Foods Market IP, L.P.

Cover photos: Credit: Jennifer Scheib, NREL/PIX 18606, NREL/PIX 18607, \& NREL/PIX 18608

Installing doors on medium-temperature cases saves energy in grocery stores.

Whole Foods Market works to reduce lighting power density while maintaining adequate lighting on product displays.

Whole Foods Market uses a combination of ambient and accent lighting as well as daylighting to reduce energy use in its stores. 


\section{TABLE OF CONTENTS}

Whole Foods Market New Construction Summary . . . . . . 3

Whole Foods Market New Construction Case Study _ _ $\quad 6$

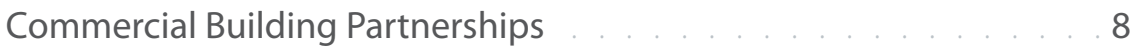

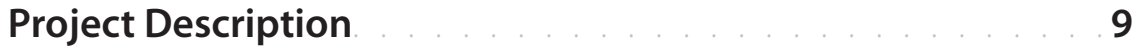

Making the Business Case $\ldots \ldots \ldots$

Energy Performance at the New Raleigh Store _ . . 10

Project at a Glance $\ldots \ldots \ldots \ldots \ldots$

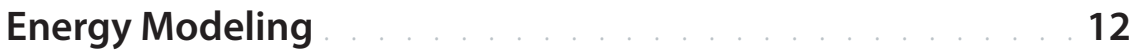

Begin With the Basics $\ldots \ldots \ldots$

Energy Efficiency Measures (NREL-Recommended) $\ldots \ldots \ldots$

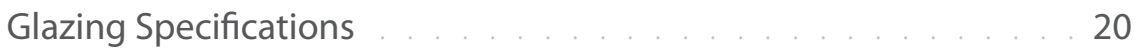

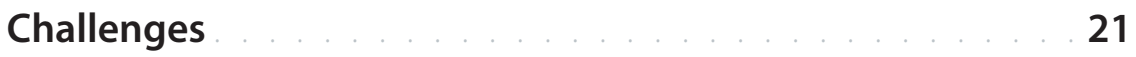

A Whole Building for Whole Foods $\quad 22$

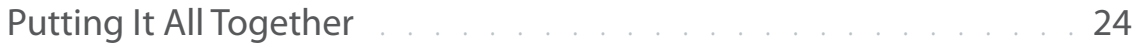

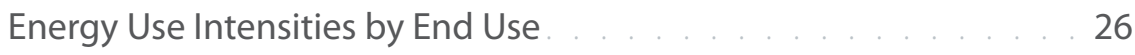

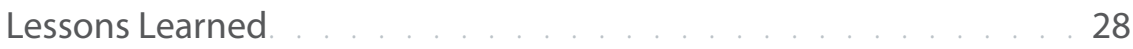

References $\ldots \ldots \ldots \ldots$

Acronyms $\ldots \ldots \ldots \ldots$

Glossary $\ldots \ldots \ldots \ldots$ 
"Whole Buildings are a focus at Whole Foods Market, and the company has had internal green building standards and practices in place for years" says Kathy Loftus, global leader, sustainable engineering, maintenance, and energy management for Whole Foods Market. "But our participation in the U.S. Department of Energy's Commercial Building Partnerships provides an opportunity for us to dig into the details of how our stores use energy in ways that we haven't explored before." 


\section{FOOD RETAILER CHECKLIST}

Based on the preliminary results from Whole Foods Market's new construction CBP project, food retailers can benefit the most from their investments in energy efficiency by implementing the following measures. The EEMs with plus signs are likely to be the most cost-effective strategies in existing buildings.

\section{REFRIGERATION}

$\checkmark$ Add doors to medium-temperature cases where appropriate, and night curtains to remaining open medium-temperature cases.

${ }^{*}$ Replace light fixtures in refrigerated cases and walk-in coolers with light-emitting diodes (LEDs).

${ }^{4}$ Replace permanent-split capacitor and shaded pole motors with high-efficiency, electrically commutated motors for evaporator fans.

$\checkmark$ Reduce electricity use for anti-sweat door heaters by aggressively controlling them in response to the store humidity levels.

$V^{+}$Use variable-speed fans for the condensers.

Install electronic expansion valves for the lowtemperature system and reduce the minimum saturated condensing temperature from $75^{\circ} \mathrm{F}$ to $55^{\circ} \mathrm{F}$ for both the medium- and low-temperature systems.

Capture waste heat for air and service water heating.

\section{LIGHTING}

$V^{+}$Reduce total installed lighting load (not including refrigerated case lighting) to $1.0 \mathrm{~W} / \mathrm{ft}^{2}$.

$\nu^{+}$Reduce lighting levels during after-hours stocking and cleaning.

Consider using LEDs for display applications throughout the store.

Install skylights and control lights in response to available daylight.

\section{National Renewable Energy Laboratory}

1617 Cole Boulevard, Golden, Colorado 80401

303-275-3000 • www.nrel.gov

NREL is a national laboratory of the U.S. Department of Energy

Office of Energy Efficiency and Renewable Energy

Operated by the Alliance for Sustainable Energy, LLC

NREL/FS-5500-50790 • April 2011

This summary is based on "Thinking Like a Whole Building: A Whole Foods Market New Construction Case Study," which is available at

www.nrel.gov/docs/fy11osti/50056.pdf.

\section{HVAC}

$V^{+}$Decrease total airflow rate to about $0.6 \mathrm{cfm} / \mathrm{ft}^{2}$ in the dry goods and grocery sections.

$V^{+}$Optimize the main air-handling unit by independently controlling humidity and temperature.

\section{KITCHEN EXHAUST}

$V^{+}$Install side panels on exhaust hoods to achieve a lower exhaust flow rate and capture all exhaust fumes.

$\checkmark$ Install demand ventilation sensors and controls to reduce exhaust flow (and the required make-up air) when there is no cooking.

\section{ENVELOPE}

Add a vestibule to store entrances and exits and offset the doors to reduce the airflow into the building when both sets of doors are open.

$\checkmark$ Reduce total glazing area and use more efficient glazing.

\section{MORE GOOD IDEAS}

Reduce refrigerant charge AND save energy. Design refrigeration systems to minimize greenhouse gas emissions, considering both refrigerant leaks and the emissions from the electricity generated to run the system.

Expect more of manufacturers. Set performance goals and place the responsibility for meeting those goals on HVAC manufacturers and other vendors.

Use equipment only as needed. Save energy and money by using equipment to provide the function required as needed rather than running it constantly at full power.

Use efficient kitchen equipment. Select ENERGY STAR ${ }^{\circledast}$ qualified equipment when possible, maintain it properly, and turn it off when not in use.

Reduce plug loads. Use power savings settings on computers and point of sale equipment, consolidate personal office equipment with a multifunction device, and use load management devices on refrigerated vending machines. 
Whole Foods Market uses a combination of ambient and accent lighting to highlight the products in its stores.

Credit: lan Doebber, NREL/PIX 18609

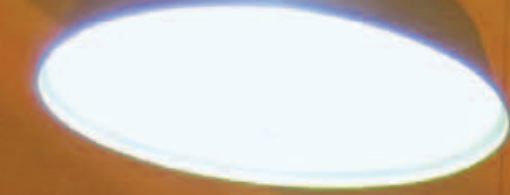

\section{i}

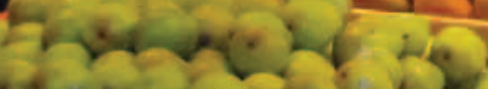

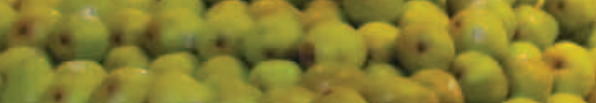

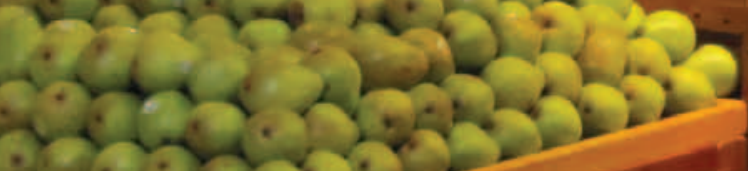

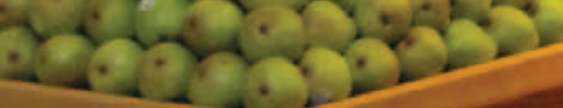

2.32 


\section{U.S. Department of Energy's \\ Commercial Building Partnerships}

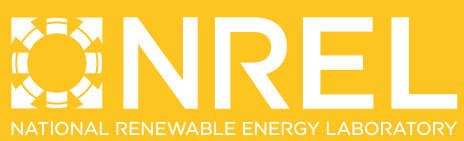

\section{THINKING LIKE A WHOLE BUILDING: A WHOLE FOODS MARKET NEW CONSTRUCTION CASE STUDY}

Whole Foods Market is the world's leading natural and organic foods retailer, with more than 300 stores in North America and the United Kingdom. Whole Foods Market's participation in the U.S. Department of Energy's (DOE) Commercial Building Partnerships (CBP) is a natural extension of its values and vision.

"Whole Buildings are a focus at Whole Foods Market, and the company has had internal green building standards and practices in place for years," says Kathy Loftus, global leader, sustainable engineering, maintenance, and energy management for Whole Foods Market. "But our participation in CBP provides an opportunity for us to dig into the details of how our stores use energy in ways that we haven't explored before." 


\section{COMMERCIAL BUILDING PARTNERSHIPS}

The U.S. Department of Energy's (DOE) Commercial Building Partnerships (CBP) (DOE $2010 b$ ) is a public/private cost-shared effort that provides an opportunity for commercial building owners and operators (Partners) to cost-effectively improve the energy efficiency of their facilities. Each Partner agrees to pursue ambitious energy-saving goals - a 50\% reduction in energy use over Standard 90.1-2004 in a new construction project and a 30\% reduction over Standard 90.1-2004 or current energy use in a retrofit. Partners also agree to provide the resources necessary to meet those goals. All Partners are members of the DOE Commercial Building Energy Alliances (DOE 2010a), and the lessons learned during the CBP projects will be shared among Alliance members as well as with other interested commercial building professionals.

DOE representatives, national laboratory staff, and private sector technical experts help Partners meet their energy goals with acceptable returns on investment based on their business models. Partners can thus incorporate ideas and strategies into their projects that might seem too expensive or technologically challenging to tackle without the resources and technical expertise available through CBP.
The CBP projects serve as test beds and training centers for innovative building-related research, and demonstrate how energy use can be reduced dramatically and cost effectively in commercial buildings. The new construction projects also provide an opportunity to corroborate the recommendations contained in the technical support documents (TSDs) for $50 \%$ energy savings. The TSDs provide the basis for the forthcoming 50\% Advanced Energy Design Guides developed by DOE and the national laboratories in collaboration with the American Society of Heating, Refrigerating and Air-Conditioning Engineers (ASHRAE) and other partners. DOE, the Pacific Northwest National Laboratory, and the National Renewable Energy Laboratory (NREL) develop the technical support documents, including a Grocery Store 50\% Energy Savings Technical Support Document (Leach et al. 2009).

The lessons learned from these projects will soon be published in case studies. Simple decision tools to assess the business cases for various energy efficiency measures are also under development. These tools will help facilitate energy savings across the commercial building sector. This case study is a snapshot of the progress to date on the Whole Foods Market CBP new construction project in Raleigh, North Carolina.

Adding doors to medium-temperature refrigerated cases in a supermarket can reduce the cooling load in those cases by about $65 \%$. 
Whole Foods Market is working with the National Renewable Energy Laboratory (NREL) on a retrofit and a new construction CBP project. This case study is a snapshot of the progress to date of the Whole Foods Market CBP new construction project in Raleigh, North Carolina. It describes the successes and challenges of working collaboratively and using strategies and technologies that meet Whole Foods Market's business criteria to dramatically reduce energy consumption. The new Raleigh store is currently under construction, and is expected to be completed in the spring of 2011.

This case study demonstrates the value of the project to Whole Foods Market, the degree to which the involvement of members of NREL's Commercial Buildings Research Group helped stretch the team's thinking about how to reduce energy consumption, and the lessons learned that are useful to the broader food sales industry. These lessons will be shared among members of the Commercial Building Energy Alliances (DOE 2010a) as well as with other interested commercial building professionals.

\section{PROJECT DESCRIPTION}

The new Whole Foods Market store in Raleigh, North Carolina, is a single-story $40,000 \mathrm{ft}^{2}$ standalone store. Although each Whole Foods Market is unique, this store is representative of other Whole Foods Market stores, and the energy efficiency measures (EEMs) used here can be deployed to these stores and to other buildings in the U.S. food sales subsector.

The store is located in DOE climate zone 4A, mixed-humid, which receives more than 20 inches of annual precipitation, has 5,400 or fewer heating-degree days, experiences monthly average outdoor temperatures below $45^{\circ} \mathrm{F}$ during the winter months, and may have significant cooling loads and high humidity during the summer.
"Whole Foods Market store development leaders work sideby-side with local operations leaders," according to Loftus, "We make it clear that the effort to improve energy efficiency makes sound business sense in addition to being the right thing to do."

\section{MAKING THE BUSINESS CASE}

Whole Foods Market is organized around regional offices, and the leaders and team members of individual stores have some autonomy. Their decisions are informed by Whole Foods Market's core values and guided by its stated commitment to care for the environment and the communities in which it operates.

That commitment includes creating a comfortable and enjoyable shopping experience, maintaining a healthy bottom line, and minimizing its environmental impacts. Reducing energy use is one way to meet this commitment, but energy reduction strategies must in every case make business sense.

Whole Foods Market's decentralized business model initially presented challenges to improving energy efficiency. This business structure has many advantages, such as each region's and store's relationships with local organizations, suppliers, and growers. But the culture does not include a mechanism for dictating energy efficiency standards, so energy savings strategies were initially deployed on a case-bycase basis.

"Internal communication was key," says Loftus. "Once we developed ways of communicating the benefits of improved energy efficiency for the environment, shareholders, and everyone else- and we circulated the success stories-it was easy for leaders to adopt best practices." 
To keep everyone in the loop, executive level Whole Foods Market teams participate in monthly conference calls and meet face-toface at least twice every year. The Energy and Maintenance and Store Development teams maintain a collaborative website for the entire company that chronicles successes and lessons learned.

"Whole Foods Market store development leaders work side-by-side with local operations leaders," according to Loftus. "We make it clear that the effort to improve energy efficiency makes sound business sense in addition to being the right thing to do."

Another consideration for Whole Foods Market is that it leases its buildings. In new construction projects, the developer is responsible for building the core and shell (broadly defined as the structure, envelope, and building-level systems such as heating, ventilation, and air-conditioning [HVAC]), and the regional construction team manages the process of finishing the interior.

"We're getting much better at writing specifications into the leases," says Loftus. "And the process of working with NREL through CBP will help us be even more precise about store performance requirements."

"Supermarkets are energy intensive," according to Mike Farish, store development leader for the Whole Foods Market south region and project manager for the new Raleigh store." And Whole Foods Market stores are more energy intensive than most supermarkets because of our in-house bakeries and extensive food preparation areas."
Whole Foods Market is committed to an energy reduction goal of $25 \%$ compared with 2008 baseline use at all stores by 2015. As a CBP Partner, Whole Foods Market has also agreed to target energy savings compared with the American National Standards Institute/ American Society of Heating, Refrigerating and Air-Conditioning Engineers / Illuminating Engineering Society of North America (ANSI/ ASHRAE/IESNA) Standard 90.1-2004 of 50\% in the Raleigh project.

Determining paybacks for innovations with many variables and no track record can be difficult. Whole Foods Market nominally uses a three-year simple payback as a project-screening guideline for retrofits, but may consider longer paybacks for new stores. Whole Foods Market does not have strict rules about paybacks or other methods of determining cost-effectiveness, and other business values also play a role in the decision-making process.

\section{ENERGY PERFORMANCE AT THE NEW RALEIGH STORE}

Energy use intensity (EUI) describes a building's energy use in a way that can be compared across buildings with very different floor areas. To calculate EUI, the total energy consumed in one year, generally expressed in units of $\mathrm{kBtu}$ (thousands of British thermal units) or kWh (kilowatt-hours), is divided by the total floor space. Compared with other retail building types, supermarkets tend to have higher EUIs because of refrigeration and cooking equipment. The dominant energy loads for most other retail building types are lighting and HVAC.

"Supermarkets are energy intensive," according to Mike Farish, store development leader for the Whole Foods Market south region and project manager for the new Raleigh store.

"And Whole Foods Market stores are more energy intensive than most supermarkets because of our in-house bakeries and extensive food preparation areas." 


\section{PROJECT AT A GLANCE}

\section{Project Type \\ Retail grocery store \\ Project Description \\ Construction of a typical single-story \\ standalone store \\ Project Size \\ $40,000 \mathrm{ft}^{2}$}

\section{Project Location \\ Raleigh, North Carolina}

\section{Climate Zone}

$4 \mathrm{~A}$, mixed-humid

\section{Square Footage Controlled by Partner}

11 million in the United States

Expected Energy Savings (\%) and Basis for Comparison

41\% over Standard 90.1-2004

\section{Expected EUI of Final Project}

$208 \mathrm{kBtu} / \mathrm{ft}^{2} \mathrm{yr}$

\section{Potential for Replication}

Very good-although Whole Foods Market does not use a prototype per se, this store is representative of its near-term new construction projects and is similar to other buildings in the food sales subsector.

\section{Carbon Dioxide Emissions}

\section{Avoided}

2.6 million lb/yr

\section{Energy Savings}

$\sim 1.4$ million $\mathrm{kWh} / \mathrm{yr}$ electricity $\sim 15,500$ therms/yr natural gas
Whole Foods Market South Region Team

Mike Farish

Scott Hewett

BJ Leonard

Kathy Loftus

Tom Patrick

Whole Foods Market

Design Team

e2s

Michael Guldenstern

ochsnerEFS, p.c.

Dean Ochsner

GreenbergFarrow

Mitch Deutsch

Justin Hardy

Western Extralite

Mark Kaner

NREL Principal Investigator

Paul Torcellini

NREL Project Lead

Michael Deru

NREL Project Engineers

Eric Bonnema

Ian Doebber

Jennifer Scheib

NREL Technical Monitors

Adam Hirsch

Greg Stark

\section{NREL Subcontractors}

CDH Energy Corporation

Hugh Henderson

CTA Architects \& Engineers

Rob Arthur

Jim Armer
Using LEDs in place of T-8 fluorescents in medium-temperature cases reduces lighting power use in these cases by $50 \%$, because LED lights illuminate product as well as or better than fluorescents using less power. 
other energy use information from similar new Whole Foods Market stores. Instead of focusing on individual EEMs, they optimized the design by analyzing the whole building as a system.

Modeling software is still evolving, and this Whole Foods Market project helped NREL researchers identify some limitations in EnergyPlus. In particular, they faced challenges modeling the details of advanced HVAC, refrigeration, and kitchen exhaust systems.

Work is now under way to resolve these limitations. In collaboration with Partners, refrigeration consultants, and software developers at other national laboratories, NREL has made good progress by comparing modeling results with tried-and-true engineering experience and detailed submetered electrical data (Doebber 2010). For example, Therese Stovall at Oak Ridge National Laboratory has incorporated some of NREL's recommendations into the new EnergyPlus release. NREL researchers and others can now model basic to advanced refrigeration systems with a high level of confidence.

This software refinement is an example of simulation engine improvement that resulted directly from the collaboration among national laboratory personnel, private sector technical experts, and CBP Partners. Without DOE's investment in technical assistance, it is unlikely that the time or money would have been available to explore the complexities of modeling refrigeration in supermarkets. Now the results of this research will be available to all future grocery store designers.

\section{This software refinement is an} example of simulation engine improvement that resulted directly from the collaboration among national laboratory personnel, private sector technical experts, and CBP Partners.

\section{BEGIN WITH THE BASICS}

Descriptions of the three systems NREL examined most closely-refrigeration, kitchen exhaust, and lighting-follow. (See Energy Efficiency Measures, page 16, for information about the envelope and HVAC systems.)

\section{REFRIGERATION}

Refrigeration uses significant energy in a supermarket, and accounts for about 39\% of the total energy use in new Whole Foods Market stores (see Energy Use Intensities by End Use, page 26). Supermarkets require low-temperature refrigerated cases for frozen foods (these are usually maintained at about $-10^{\circ} \mathrm{F}$ ) and medium-temperature cases for dairy, packaged seafood, packaged produce, cheese, beverages, meat, and deli goods (these are typically maintained at $28^{\circ} \mathrm{F}$ to $36^{\circ} \mathrm{F}$ ).

Adding doors to medium-temperature cases can reduce their cooling load by about $65 \%$ (Fricke and Becker 2010). Modeling results from the feasibility study indicate that adding doors to 132 linear feet of medium-temperature cases could reduce the required refrigeration capacity by about 10 tons ( $34 \mathrm{~kW})$, roughly $25 \%$ of the entire medium-temperature cooling load. Whole Foods Market intends to use the Raleigh store to verify the savings from adding doors before changing its refrigeration design in other stores.

On the doors of the low-temperature cases in the new store, Whole Foods Market specified electric resistance anti-sweat door heaters to minimize condensation. Whole Foods Market reduced the amount of energy these heaters use by implementing an aggressive anti-sweat heat-to-dew point control that quickly reduces the energy delivered to the anti-sweat devices as the dew point decreases.

The new store will maintain a dew point of about $50^{\circ} \mathrm{F}$ compared with a typical dew 
point setting of about $55^{\circ} \mathrm{F}$. The air-handling unit (AHU) serving the sales floor is equipped with a solid desiccant wheel, a dehumidification device capable of efficiently achieving the lower dew point.

The dew point setting represents a balance between saving refrigeration energy through reduced latent cooling load, anti-sweat heating, and defrost load, and increasing HVAC energy to dehumidify to a lower dew point. The latent cooling load refers to the energy required to remove the heat released when moisture in the air condenses onto the case coil.

\section{Replacing T-8 fluorescents with light-emitting diodes (LEDs) in the refrigerated cases reduces lighting power use from $18 \mathrm{~kW}$ to $9 \mathrm{~kW}$, a $50 \%$ decrease.}

The dew point "sweet spot" can be contentious, and depends on the refrigeration system, the HVAC system, and the climate. Eventually, the increased energy required for the HVAC system to further dry the air consumes more energy than can be saved through reduced energy consumption for refrigeration. Although some claim that the dew point set point should be $45^{\circ} \mathrm{F}$, Whole Foods Market chose the more conservative $50^{\circ} \mathrm{F}$. The dew point will be modified throughout the year during normal operation to determine which set point yields the lowest net energy use.

Night curtains-highly reflective shades that are manually drawn over the fronts of open medium-temperature cases every evening when the store closes-also save energy. Night curtains lower the cooling load on the refrigeration case by about $40 \%$ during unoccupied periods (Hussman 2010).
Replacing T-8 fluorescents with light-emitting diodes (LEDs) (DOE 2010d) in the refrigerated cases reduces lighting power use from $18 \mathrm{~kW}$ to $9 \mathrm{~kW}$, a $50 \%$ decrease. This change also reduces the additional cooling load from lamp and ballast heat. The savings is due to the greater directional control of LEDs lights, which illuminate product as well as or better than fluorescents using less power. Also, unlike LEDs, the light output of fluorescent lights decreases as they get colder- a particular concern in this application.

Another energy-saving strategy is to replace most standard-efficiency (permanent-split capacitor) motors with high-efficiency (electrically commutated) ones for the evaporator fans. Not all the fans were replaced because some specialized manufacturers did not sell fans with electrically commutated motors. Despite this, the total case fan power draw decreased $36 \%$, from $15.0 \mathrm{~kW}$ to $9.6 \mathrm{~kW}$.

Using variable-speed fans on the low- and medium-temperature case air-cooled condensers saves fan energy by matching fan power to the condenser cooling load. This strategy provides better control of the refrigerant temperature leaving the condenser. Therefore, it saves energy and provides better control over the refrigeration system.

Yet another refrigeration EEM is to allow the minimum condensing temperature on both systems to drop below their typical minimum settings. In the Raleigh store, that meant setting the minimum saturated condensing temperatures of the low- and medium-temperature cases to $55^{\circ} \mathrm{F}$ rather than a minimum of $75^{\circ} \mathrm{F}$. Whole Foods Market will also use electronic expansion valves to maintain temperature control in low-temperature cases.

Whole Foods Market also had to deal with the competing priorities of reducing refrigerant charge and saving energy. The U.S. Environmental Protection Agency (EPA) has 


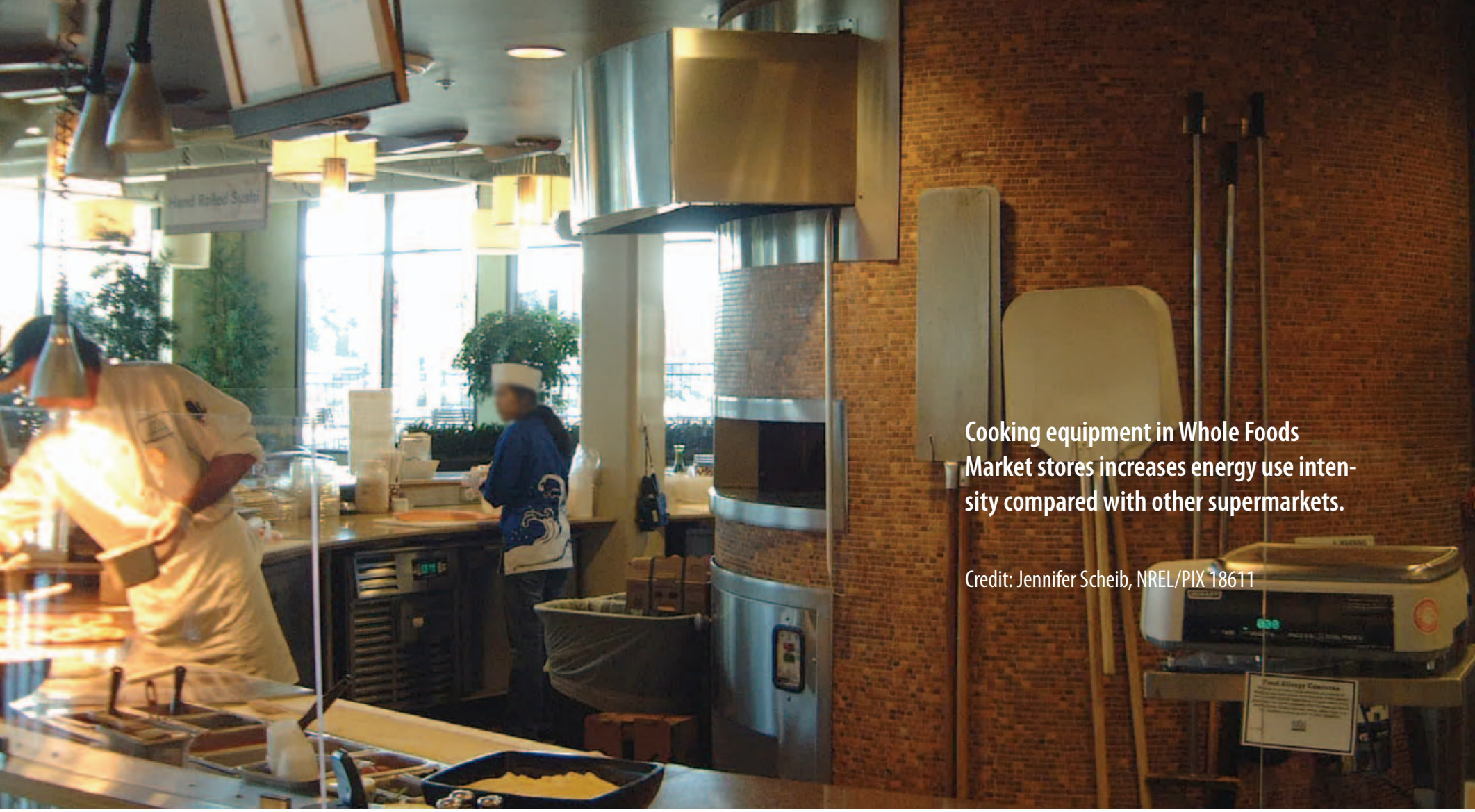

issued regulations under the Clean Air Act designed to maximize the recovery and recycling of refrigerants during the service, repair, or disposal of refrigeration equipment. EPA also administers the voluntary GreenChill Advanced Refrigeration Partnership, which encourages food retailers to use environmentally friendlier refrigerants, reduce refrigerant charge sizes, and eliminate leaks. These efforts decrease the impact of refrigerants on the ozone layer and climate change, but are typically energy neutral at best, and can even increase energy use.

\section{KITCHEN EXHAUST}

Whole Foods Market employees prepare a large amount of food, so the interactions between the kitchen and the rest of the store are significant. To maintain good indoor air quality in the kitchen and keep cooking odors and moisture out of the sales area, a significant amount of air must be exhausted to the outside. NREL suggested some strategies to reduce kitchen energy use.
Whole Foods Market uses a make-up air unit (MAU) to provide $80 \%$ of the make-up air required by the three largest exhaust hoods. The remaining 20\% comes from the rooftop unit (RTU) serving the kitchen area and the main AHU serving the sales floor to maintain the kitchen at a negative pressure. The negative pressure helps keep odors and moisture away from the sales area.

Because the air from the MAU is delivered directly in front of the exhaust hood, it does not affect comfort in the kitchen and is immediately sucked into the hood. Therefore, the air needs to be heated to only $65^{\circ} \mathrm{F}$ in the winter and cooled to $85^{\circ} \mathrm{F}$ in the summer, saving a great deal of energy.

Whole Foods Market has been using exhaust hoods that operate in response to hot temperatures or smoke from the cooking surface below for a couple of years. NREL encouraged the use of these hoods in the new Raleigh store, and Whole Foods Market chose hoods that operate at a $80 \%$ flow rate when there is no smoke, and a $100 \%$ flow rate when temperatures are high or smoke is present. 


\section{NREL-RECOMMENDED ENERGY EFFICIENCY MEASURES}

The Commercial Building Partnerships (CBP) process is collaborative, and it is not always clear which participant recommended which energy efficiency measure (EEM). This list indicates the EEMs that Whole Foods Market adopted based on NREL's direct recommendation or based on a consensus recommendation from the group of NREL researchers, privatesector subcontractors, and Whole Foods Market personnel.

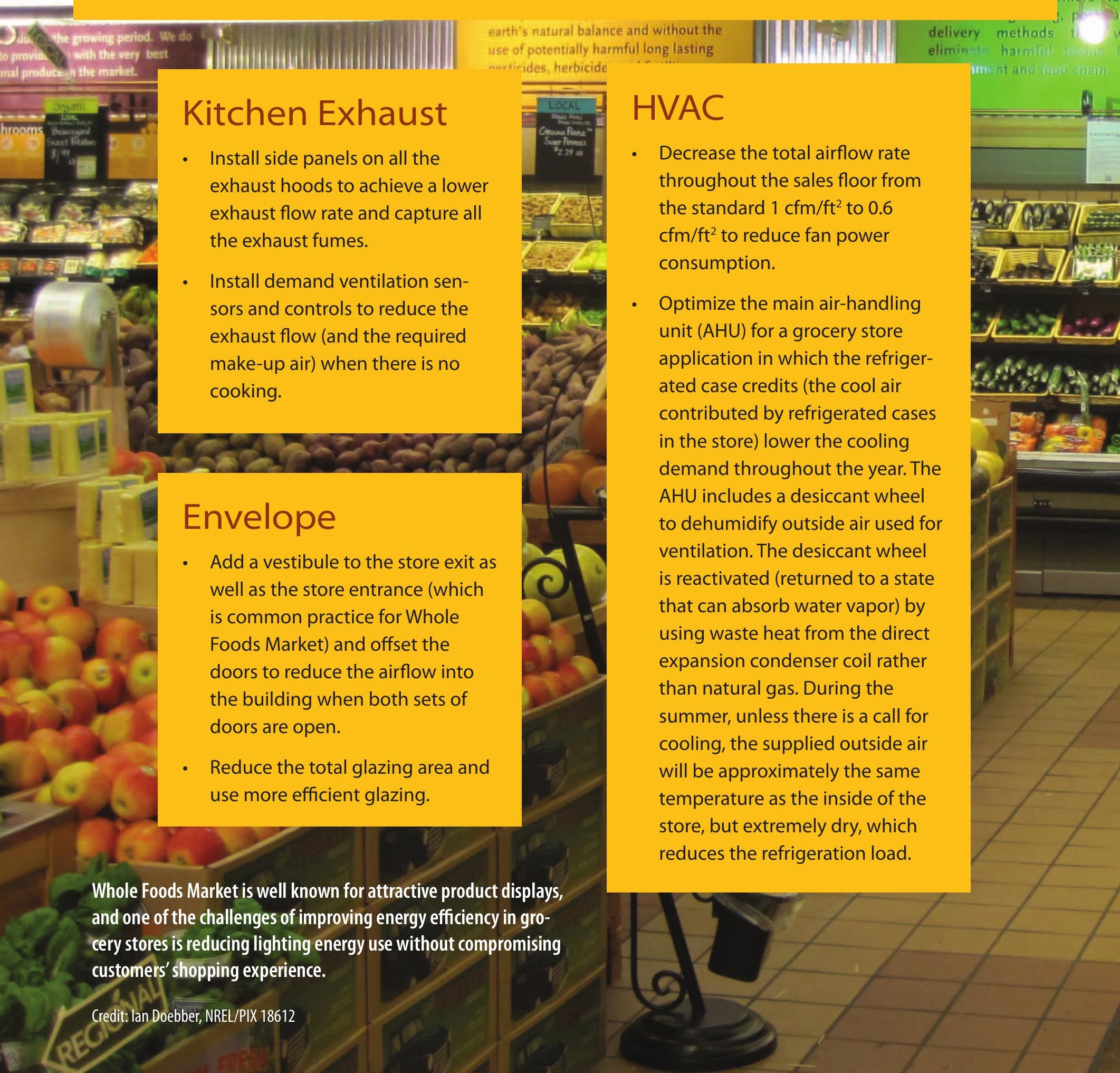




\section{Refrigeration}

- Add doors to medium-temperature cases for packaged produce, packaged seafood, cheese, and dairy.

- Add night curtains to open medium-temperature cases that display non-packaged produce, meat, and prepared foods.

- Replace T-8 fluorescents in the refrigerated cases and walk-in coolers with LEDs.

- Replace most permanent-split capacitor motors with high-efficiency, electrically commutated motors for the evaporator fans.

- Reduce electricity use for anti-sweat door heaters by aggressively controlling them in response to the store dew point, which will be maintained at $50^{\circ} \mathrm{F}$ using desiccant technology in the main air-handling unit.

- Use variable-speed fans to cool the low-temperature condensers.

- Install electronic expansion valves and set the minimum saturated condensing temperature of the low- and medium-temperature cases to $55^{\circ} \mathrm{F}$ rather than a minimum of $75^{\circ} \mathrm{F}$.

- Capture waste heat for both air and service water heating.

\section{Lighting}

- Reduce the total installed lighting load from the $2.4 \mathrm{~W} / \mathrm{ft}^{2}$ code-compliant maximum (ambient and accent lighting) to approximately $1 \mathrm{~W} / \mathrm{ft}^{2}$ by using a combination of linear fluorescent, metal halide, and light-emitting diodes (LEDs) fixtures to provide an ambient layer throughout the store and an additional accent layer throughout the sales area.

- Weigh the efficacy, color rendering, and cost of LED fixtures to determine the best sales areas and back-of-house applications.

- Use more aggressive glare control than is typical in Whole Foods Market stores.

- Optimize the distribution of skylights and associated area lamp selection for daylight controllability.

- Control the ambient and fluorescent lighting in the dry goods section by using bi-level configuration for daylighting and stocking time-of-use reduction. 
NREL recommended installing side panels on all the exhaust hoods to allow for a lower exhaust flow rate and still capture all the exhaust fumes. This reduction in outdoor air intake reduces heating and cooling demand on the MAU, the main AHU, and the kitchen RTU.

\section{LIGHTING}

NREL researchers performed a general lighting study that looked at several options for improving lighting efficiency. They used a suite of computer programs called Radiance (LBL 2010) to show how the store interior would appear with skylights and different electric lighting configurations in the dry goods area.

The purpose was to facilitate communication with the design team about the aesthetic effects of various lighting and daylighting configurations. NREL performed a qualitative analysis to help all involved visualize how four scenarios-an open ceiling with no skylights, an open ceiling with an exposed roof structure and skylights, a lay-in tile ceiling at 14 feet above the finished floor, and an open ceiling with gondola-mounted fixtures-would look and feel.

Second, NREL researchers used a SPOT (Sensor Placement + Optimization Tool) simulation of an open ceiling with skylights to determine the energy savings resulting from dimming or bi-level switching of the electric lights (AEC 2010). SPOT helps designers quantify the electric lighting and daylighting characteristics of a space over time and establish the optimal photosensor placement for maximum energy savings. They used a variety of skylight-to-floor area ratios and fixture/lamp combinations to create lighting power density (LPD) reduction schedules that could be used in EnergyPlus. LPD is a measure of electrical power used to provide lighting to a space, expressed in watts per square foot $\left(\mathrm{W} / \mathrm{ft}^{2}\right)$.
The design team settled on a $4 \%$ SFA in dry goods and back-of-house corridors, bi-level linear fluorescents with LED accents in dry goods, and metal halide ambient and accent lighting in produce, meat, and bakery sales. The lamps in the bi-level fixtures are wired separately so one lamp in each can be turned off independently to reduce lighting power in response to daylight and after-hours stocking schedules. These fixtures are not dimmable, but can be off, $50 \%$ on, or $100 \%$ on.

"The NREL engineers brought an amazing level of expertise and detail orientation to the project," says Farish."It would have taken more time and cost more for our engineers to drill down that far, but our design and construction team benefited from learning about the intricacies of energy use."

Lamps were selected based on a balance of efficacy, controllability, color rendering, and cost. Compared with the Whole Foods Market new construction standard, the SPOT/EnergyPlus results showed whole-building energy savings of about $4 \%$ from adding daylighting and reducing LPD in the dry goods and checkout areas, and less than $2 \%$ whole-building savings from LPD reduction in the produce area.

NREL's recommendations for the skylight glazing (see Glazing Specifications on page 20) included a heat transmission value (U-value) that represents a 60\% improvement over Standard 90.1-2004, a solar heat gain coefficient (SHGC) slightly better than 90.1, and a diffuse visible light transmittance (VLT) higher than $50 \%$. 
Whole Foods Market accepted NREL's skylight glazing recommendations as part of a living specification document (a set of flexible requirements designed to accommodate new products and processes), but installed units with slightly lower performance properties because of product availability and preference. The SHGC of the selected skylight is higher than NREL's recommendation, but Whole Foods Market's previous success with quality installation (no leaking, acceptable appearance) made it the more appropriate choice. An EnergyPlus simulation that compared the selected skylight with products that met the NREL criteria did not show enough additional energy savings to justify rejecting a trusted product.

The skylight light wells provide diffuse light because of the 40-inch depth and white coating. NREL also developed spreadsheets to compare available skylight and glazing properties and used that information to edit the list of building shell requirements and specifications that Whole Foods Market prepares for the developer.

NREL researchers used path diagrams of the sun's position and height at different times of the year and day to refine the front of store shading to facilitate daylighting and mitigate glare. They also suggested a lower windowto-wall ratio (WWR) in the front of the store. Whole Foods Market decided to lower the WWR from the baseline, and added an interior trellis to supplement the glare control provided by the exterior canopy. Whole Foods Market's final shading configuration was a compromise between the NREL recommendations and Whole Foods Market's previous front-of-store design. (For the vertical glazing specifications, see Glazing Specifications on page 20.)

Finally, NREL and the Whole Foods Market lighting representative used spreadsheets and the Lighting Analysts AGI32 simulation tool to weigh the cost, quantity of light, and wattage of LED fixtures for different applications compared with Whole Foods Market's typical lighting fixture specification. NREL used this information to determine the best applications for LED technology, which included track, strip, and refrigerated case and walk-in cooler lighting.

The result is an LPD reduction in ambient and accent lighting from the $2.4 \mathrm{~W} / \mathrm{ft}^{2}$ Standard 90.1-2004-compliant baseline for a typical new Whole Foods Market store to approximately $1 \mathrm{~W} / \mathrm{ft}^{2}$ for the entire new Whole Foods Market Raleigh store. The daylighting contributions from skylights and glazing in the front of the store, occupancy sensors in irregularly used rooms, and bi-level control of many fluorescent fixtures will result in additional annual energy savings. The specification refinements that resulted from NREL's simulation-based recommendations and Whole Foods Market's product experience will be included in a revised specification for other stores in the region.

\section{COMMISSIONING EXPERTISE DURING DESIGN}

Whole Foods Market brought the commissioning agent into the process as a consultant toward the end of the design process. This is typical for some Whole Foods Market regions, but was new for the south region. Although it would have been ideal to have the commissioning agent involved from the beginning of design, the agent's input was very valuable.

In addition, the agent's involvement during design created a relationship that increased both the agent's understanding of the intent of the design team and the probability of constructive interactions during the commissioning phase. Comprehensive building commissioning improves the chances that the building will operate as designed. 


\section{GLAZING SPECIFICATIONS}

NREL Recommendations for Skylights

$\begin{array}{ll}\text { U-value } & \text { less than } 0.55 \\ \text { SHGC* } & \text { less than } 0.40 \\ \text { VLT }^{* *} & \text { more than } 50 \% \text { diffuse }\end{array}$

Final Whole Foods Market Specifications for Skylights
U-value
0.50
SHGC*
0.60
$\mathrm{VLT}^{* *}$
$50 \%$ (diffuse because of 40 -inch wells and white coating)

NREL Recommendations for Vertical Glazing

$\begin{array}{ll}\text { U-value } & \text { less than } 0.40 \\ \text { SHGC }^{*} & \text { less than } 0.40 \\ \text { VLT }^{* *} & \text { more than } 30 \%\end{array}$

Final Whole Foods Market Specifications for Vertical Glazing

U-value $\quad 0.28$

SHGC* $^{*} \quad 0.27$

$\mathrm{VLT}^{* *} \quad 64 \%$

*SHGC solar heat gain coefficient

**VLT visible light transmittance

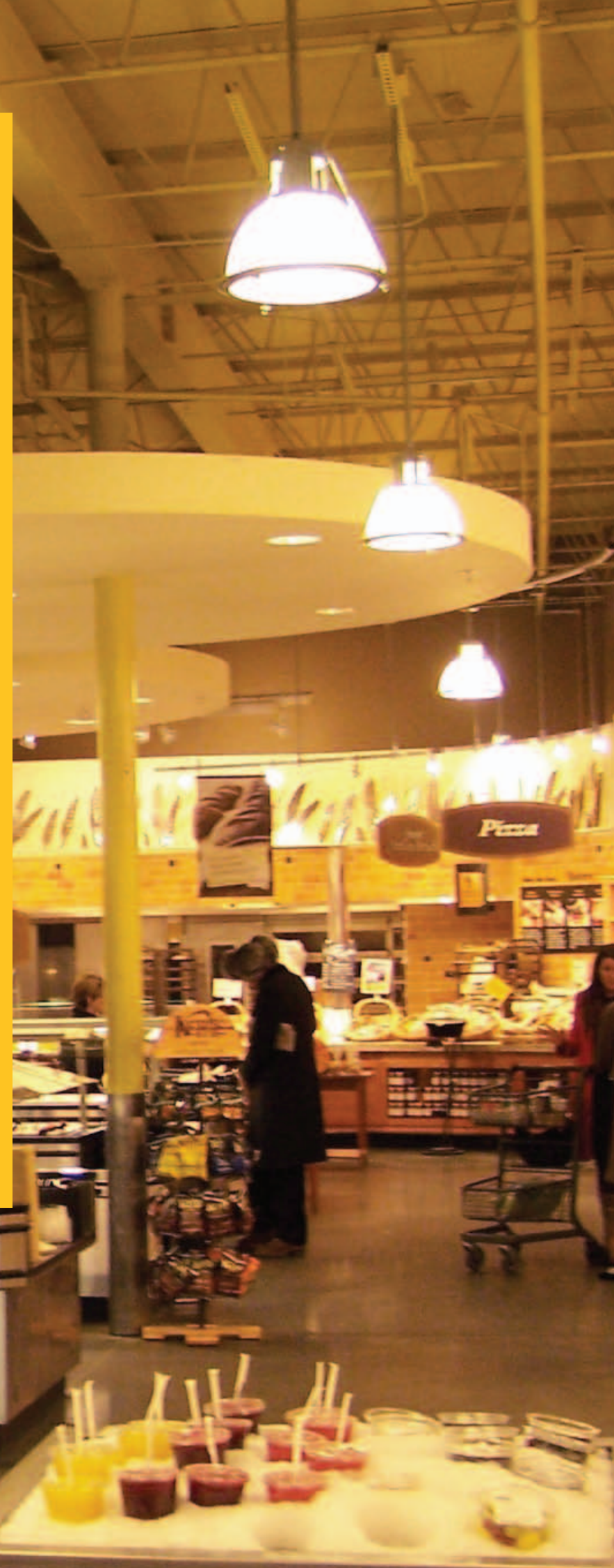
closely to reduce lighting power density while maintaining Whole Foods Market's characteristically well-lit and artful product displays.

Credit: Courtesy of Whole Foods Market, NREL/PIX 18613 


\section{DETAILS MATTER}

As the EEMs incorporated into the new Raleigh Whole Foods Market illustrate (see Energy Efficiency Measures, page 16), it often takes changes across all disciplines to significantly reduce energy use. One of the main strengths of CBP is that detailed analyses of individual systems (refrigeration, HVAC, lighting, etc.) as well as a study of how these systems interact with each other-can uncover energy-saving opportunities that might otherwise be missed.

"Although their direct experience with supermarkets was somewhat limited, the NREL engineers brought an amazing level of expertise and detail orientation to the project," says Farish.

"It would have taken more time and cost more for our engineers to drill down that far, but our design and construction team benefited from learning about the intricacies of energy use."

Whole Foods Market plans to use the strategies developed through this process in other stores. As part of CBP, NREL and its refrigeration subcontractors will carefully monitor the completed store to verify that the EEMs are operating as anticipated. It is important to learn

\section{“Detailed analyses of individual systems-as well as a study of how these systems interact with each other-can uncover energy- saving opportunities that might otherwise be missed."}

about how the building operates when it is commissioned and about what is required to ensure it maintains its energy savings over time (Scheib 2010). The information gathered during monitoring and verification will be included in an NREL technical report published after the monitoring is completed and the results are analyzed.

\section{CHALLENGES}

NREL and Whole Foods Market participants agree that their collaboration has been useful and productive. They also agree that the process had its challenges.

The time NREL required to gather the necessary information, do the simulations, vet the model, and make recommendations was not always in synch with Whole Foods Market's need to keep the project moving along quickly. The NREL researchers' job was to conduct detailed analyses so they could recommend appropriate EEMs, and Whole Foods Market's job was to design and build a store on schedule and within budget (Bonnema 2010).

Gathering information was a challenge, in part because the information was not always readily available. Whole Foods Market and NREL developed an innovative solution to this dilemma (see Lessons Learned, page 28, for more information): They put the onus on the manufacturers. The approach ranged from putting specific requirements in the request for proposal to including manufacturers' representatives in design calls to ensure that they were clear about the specifications. As a result, the design team learned crucial details not typically included in product information descriptions or specifications that helped them make informed purchasing decisions.

Another challenge was modeling the interactions between the HVAC and refrigeration systems. Food preparation is also an issue, because the new Raleigh store-like many Whole Foods Market stores-essentially houses a restaurant as well as a grocery store. Conditioning and ventilating the food preparation areas made the modeling more complex than for a typical grocery store.

Whole Foods Market is understandably cautious about adopting untried equipment and technologies, and challenged NREL researchers when they made suggestions that 
looked promising in the computer models but had not been extensively tested in the field. NREL is evaluating building-related technologies in the laboratory and in the field to address this issue. For NREL, verifying system performance with unbiased measurements of the latest technologies is a key strategy for increasing energy efficiency in commercial buildings.

Like every food retailer, Whole Foods Market has to comply with EPA regulations that govern the recovery and recycling of refrigerants. These regulations can have the unintended consequence of focusing store operators' attention on reducing the refrigerant charge without regard to the effect on energy consumption. Achieving a balance between reducing the charge and saving energy deserves study by both researchers and the refrigeration industry.

\section{A WHOLE BUILDING FOR WHOLE FOODS}

Whole Foods Market had investigated and incorporated some of the EEMs described here before working with NREL, but detailed energy modeling provided a better understanding of system interactions. For example, it helped establish which HVAC application maximized energy savings for the climate and the refrigeration and hood exhaust impacts.

"We knew there were opportunities to help bring new information about buildings and energy systems to our partners," says Loftus, "And it was a big help to have independent engineers and consultants at the table, raising questions and introducing new ideas."

All involved agreed that working through the issues was instructive.

"We had already improved the energy efficiency of our stores, and now we can do an even better job," says Farish. "Would I do it again? You bet!"

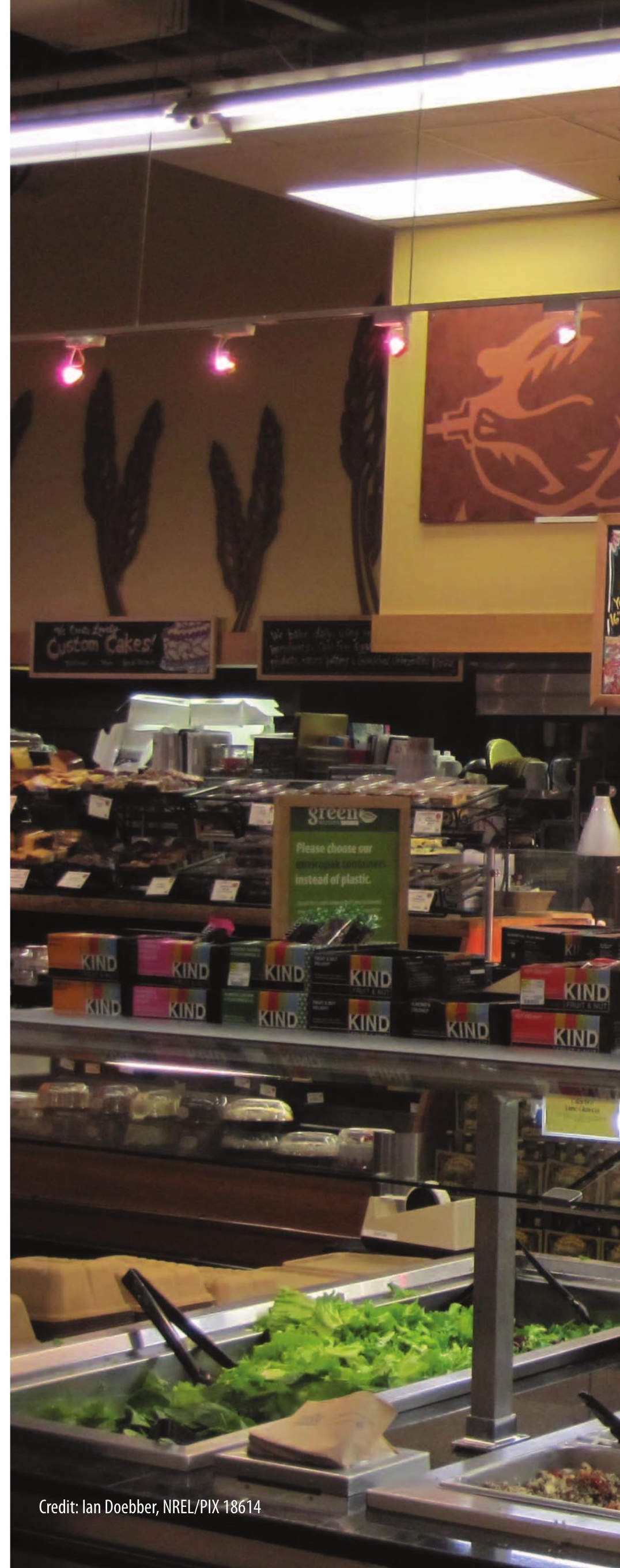




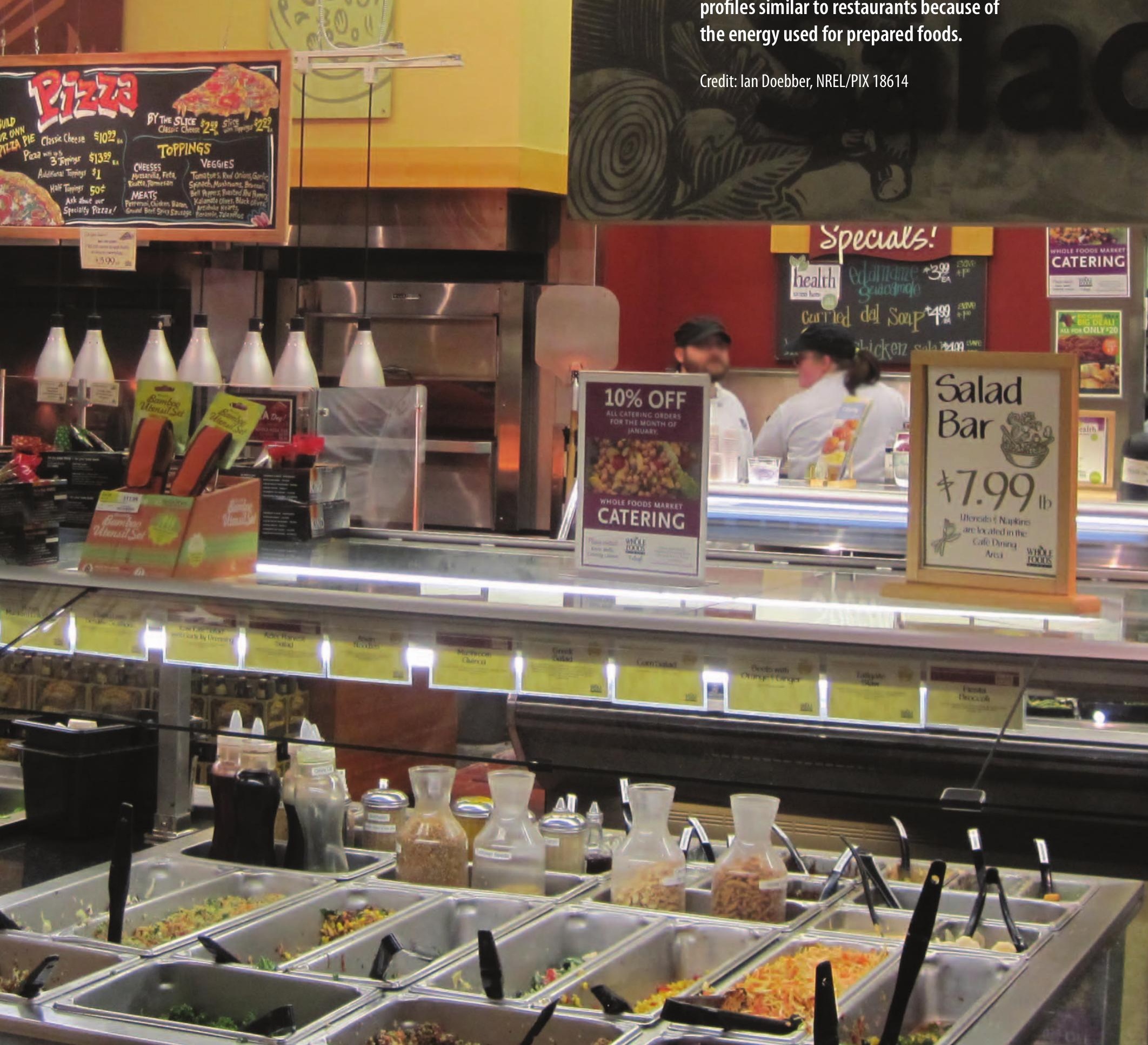

Whole Foods Market stores have energy profiles similar to restaurants because of the energy used for prepared foods.

Credit: Ian Doebber, NREL/PIX 18614

an - Were passion ate

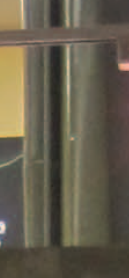




\section{PUTTING IT ALL TOGETHER}

Optimizing the energy design of a supermarket is a complex task by any measure, and is further complicated by the interactions among the various systems. Some energy efficiency measures (EEMs) work against each other; others work together synergistically. An energy model (see Energy Modeling, page 12) is a key tool for understanding and leveraging these interactions to maximize energy savings.

A few examples of the system interactions that will likely affect the new store's energy use follow, based on NREL's initial energy modeling.

\section{HVAC and Refrigeration Interactions}

Most grocery stores have open medium-temperature refrigerated cases that release cold air into the aisles. This results in stratification, with warm air rising to the ceiling and uncomfortably cold air settling near the floor. To mix the warm and cold air, operations personnel often use high HVAC flow rates, a strategy that uses a great deal of fan energy. Installing doors on these cases reduces stratification, allowing lower HVAC flow rates and saving fan energy.
On the other hand, the same cool air that contributes to stratification helps cool the space during hot weather. Installing doors isolates the cool air in the cases from the air in the sales area, decreasing the cooling load on the refrigeration system but increasing the space-cooling load. Doors on medium-temperature cases yield net annual savings because the reduced refrigeration load and heating demand in the winter outweigh the increased cooling demand in the summer.

Using the HVAC system to maintain low humidity in the store will pay off by reducing the latent cooling load on the refrigerated cases and the energy required to prevent condensation on the case doors and defrost the evaporator coils. This strategy reaches a point of diminishing returns, however, when the increased energy required for the HVAC system to further dry the air consumes more energy than can be saved through reduced energy consumption for refrigeration. The latent cooling load results from the heat released when moisture in the air changes from a vapor to a liquid (condenses) on a cold surface.
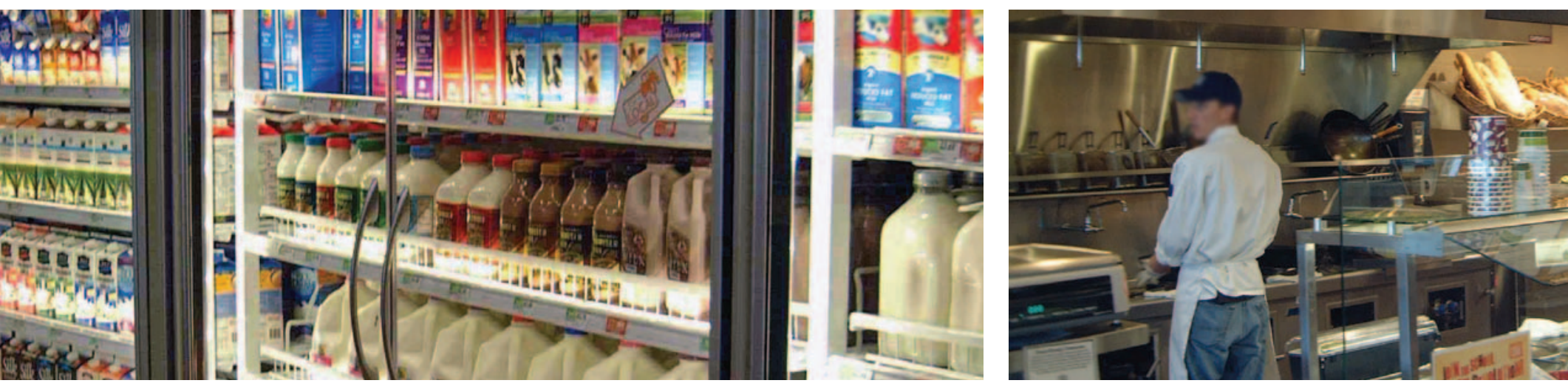

The Whole Foods Market Commercial Building Partnerships new construction project will feature doors on some mediumtemperature refrigerated cases to reduce energy use.

Whole Foods Market stores offer freshly prepared food to customers, which gives these stores energy profiles similar to restaurants. Credit: Jennifer Scheib, NREL/PIX 18615 


\section{ENERGY USE \\ INTENSITIES BY \\ END USE}

As part of the initial feasibility study to determine whether the new Raleigh Whole Foods Market store could achieve the Commercial Building Partnerships (CBP) new construction target of $50 \%$ energy savings over Standard 90.1-2004, NREL researchers developed three EnergyPlus models. The following tables and pie charts capture the results (Bonnema 2010). Please note that this is a work in progress, and the actual savings in the completed store may be different from those presented here.

\section{Model 2}

The second is built to Whole Foods Market's new store standards, and has an annual EUI of approximately 294 kBtu/ft². Whole Foods Market's specifications include lower lighting power density, improved envelope, and more efficient HVAC equipment than Standard 90.1-2004 requires. The result is an annual energy saving of about $16 \%$.

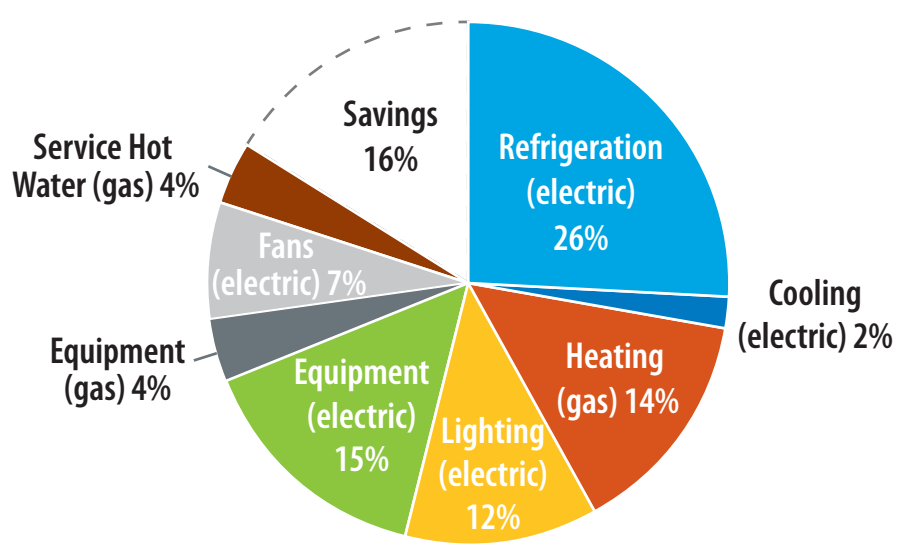

\section{Model 1}

The first represents the prescriptive specifications of Standard 90.1-2004 and ASHRAE 62.1-2004. The Raleigh, North Carolina, Whole Foods Market store built to Standard 90.1-2004 has an annual energy use intensity (EUI) of about $350 \mathrm{kBtu} / \mathrm{ft}^{2}$.

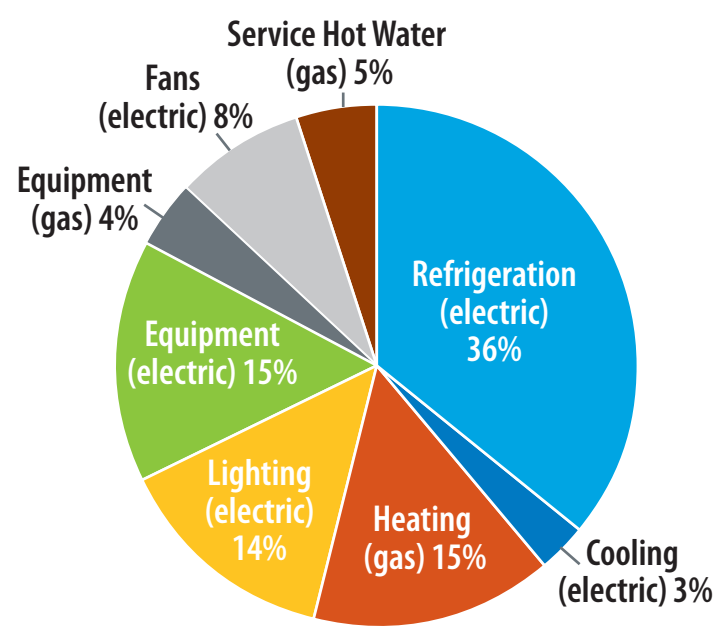

\section{Model 3}

The third version incorporates the EEMs recommended by NREL and summarized in Energy Efficiency Measures on page 16. This version has an annual EUI of about $208 \mathrm{kBtu} / \mathrm{ft}^{2}$ and an annual energy savings of about $41 \%$ over Standard 90.1-2004.

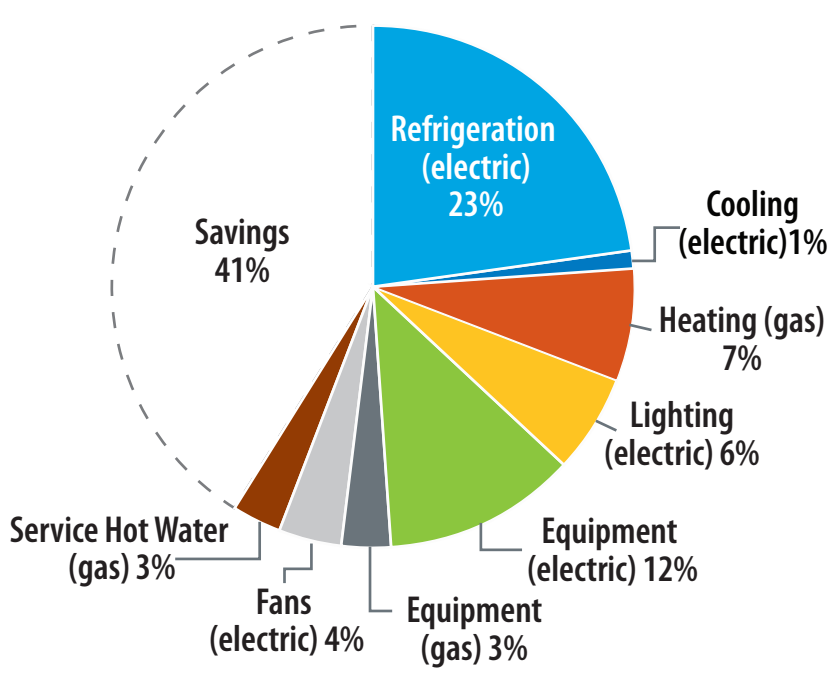




\begin{tabular}{|c|c|c|c|c|c|}
\hline \multirow[b]{2}{*}{$\begin{array}{l}\text { End Use } \\
\text { Category }\end{array}$} & \multirow{2}{*}{$\begin{array}{c}\text { Model } 1 \\
\text { Annual } \\
\text { EUI } \\
\left(\mathrm{kBtu} / \mathrm{ft}^{2}\right)\end{array}$} & \multicolumn{2}{|c|}{ Model 2} & \multicolumn{2}{|c|}{ Model 3} \\
\hline & & $\begin{array}{c}\text { Annual } \\
\text { EUI } \\
\left(\mathrm{kBtu} / \mathrm{ft}^{2}\right)\end{array}$ & $\begin{array}{l}\text { Percent Savings } \\
\text { Over } 90.1-2004\end{array}$ & $\begin{array}{l}\text { Annual EUI } \\
\left(\mathrm{kBtu} / \mathrm{ft}^{2}\right)\end{array}$ & $\begin{array}{l}\text { Percent Savings } \\
\text { Over 90.1-2004 }\end{array}$ \\
\hline Heating (gas) & 52 & 49 & $6 \%$ & 24 & $54 \%$ \\
\hline $\begin{array}{l}\text { Service hot } \\
\text { water (gas) }\end{array}$ & 17 & 14 & $18 \%$ & 9 & $47 \%$ \\
\hline Cooling (electric) & 9 & 6 & $33 \%$ & 5 & $44 \%$ \\
\hline $\begin{array}{l}\text { Lighting } \\
\text { (electric) }\end{array}$ & 49 & 42 & $14 \%$ & 21 & $57 \%$ \\
\hline $\begin{array}{l}\text { Equipment } \\
\text { (electric) }\end{array}$ & 54 & 54 & $0 \%$ & 43 & $20 \%$ \\
\hline Equipment (gas) & 15 & 15 & $0 \%$ & 12 & $20 \%$ \\
\hline Fans (electric) & 27 & 23 & $15 \%$ & 13 & $52 \%$ \\
\hline $\begin{array}{l}\text { Refrigeration } \\
\text { (electric) }\end{array}$ & 127 & 91 & $28 \%$ & 81 & $36 \%$ \\
\hline Total & 350 & 294 & $16 \%$ & 208 & $41 \%$ \\
\hline
\end{tabular}

\section{Annual Energy and Dollar Savings by End Use}

This table summarizes the potential annual as-designed energy savings over Standard 90.1-2004 as well as the annual dollar savings resulting from those energy savings in the new Raleigh store. It assumes Whole Foods Market uses all of NREL's recommended EEMs, and all operate as designed.

TOTAL DOLLAR SAVINGS* $\$ 97,245$

Elect

End Use Category

Energy

Dollar Savings Savings* Electricity Savings

\begin{tabular}{lcc}
\hline Refrigeration & $627,992 \mathrm{kWh}$ & $\$ 37,680$ \\
\hline Lighting & $382,256 \mathrm{kWh}$ & $\$ 22,935$ \\
\hline Fans & $191,128 \mathrm{kWh}$ & $\$ 11,468$ \\
\hline Equipment & $150,172 \mathrm{kWh}$ & $\$ 9,010$ \\
\hline Cooling & $54,608 \mathrm{kWh}$ & $\$ 3,276$ \\
\hline
\end{tabular}

Electricity Total $\quad 1,406,156 \mathrm{kWh}$

\begin{tabular}{lrr} 
Natural Gas Savings & & \\
\hline Heating & 11,200 therms & $\$ 9,296$ \\
\hline Service hot water & 3,113 therms & $\$ 2,584$ \\
\hline Equipment & 1,200 therms & $\$ 996$ \\
\hline Natural Gas Total & $\mathbf{1 5 , 5 1 3}$ therms &
\end{tabular}

* Based on $\$ 0.06 / \mathrm{kWh}$ for electricity and $\$ 0.83 /$ therm for natural gas 


\section{LESSONS LEARNED}

\section{Communicate}

Both NREL and Whole Foods Market agreed on the importance of regular, iterative communication. They participated in weekly conference calls that began early in the Commercial Building Partnerships (CBP) process. These interactions helped build the relationships necessary for a successful project outcome.

\section{Expect More of Manufacturers}

Putting the responsibility on equipment manufacturers to deliver the required performance was an effective strategy for cutting through sales hype and streamlining equipment comparisons. NREL and Whole Foods Market agreed that having more information about rated conditions and performance metrics for individual devices would be useful.

Rather than trying to compare the features and benefits of different HVAC systems, NREL staff worked with the design engineer to present interested manufacturers with performance metrics and let them determine whether and how their equipment could meet Whole Foods Market's requirements (Doebber 2010). Whole Foods Market selected the most efficient HVAC equipment from the multiple manufacturers who responded to the request.

This strategy provided precise information that researchers could use to improve the accuracy of the computer model. It also highlights the importance of organizations such as DOE's Commercial Building Energy Alliances, which bring building owners and suppliers together to explore ways to reduce energy use.

\section{Involve All Players Early}

Another lesson learned is that everyone involved in designing, building, and commissioning the building should be brought to the table early. For example, Whole Foods Market brought the commissioning agent into the conversation during the design. This enabled the agent to provide a detailed review of the final design and make recommendations about the design and control strategies from an operations standpoint. The agent also established a rapport with the design team, which has given him an intimate knowledge of the design and a thorough understanding of the intent of the designers and owners.

\section{Use Equipment Only As Needed}

A great deal of energy can be saved by using equipment to provide the function required at a given time rather than running it constantly at full power. In the new Whole Foods Market store, this consideration informed the choices of kitchen hoods, refrigeration condenser fans, refrigerated case anti-sweat heaters, and lighting. Careful calibration and maintenance can ensure the modeled savings are realized.

\section{Use New Thinking Before New Technologies}

All the EEMs accepted by Whole Foods Market are commercially available and can be deployed immediately to reduce energy use in other grocery and food sales establishments. 


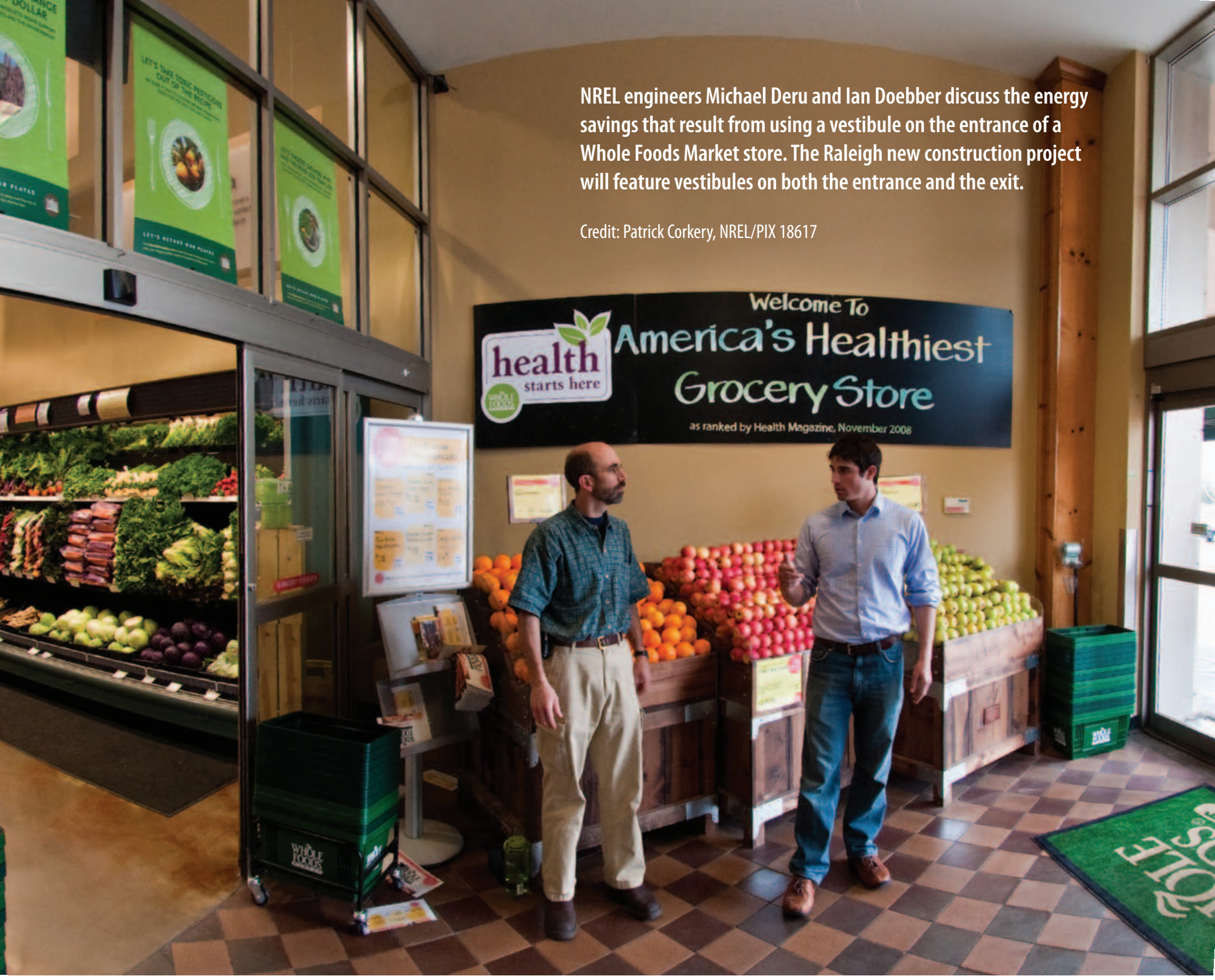

NREL staff worked with the design engineer to present interested manufacturers with performance metrics and let them determine whether and how their equipment could meet Whole Foods Market's requirements. 


\section{REFERENCES}

Architectural Energy Corporation (AEC). (2010). SPOT website. www.archenergy.com/SPOT/ index.html.

ASHRAE. (2010). Advanced Energy Design Guides website. www.ashrae.org/technology/ page/938.

Bonnema, E. (23 November 2010). Interview. National Renewable Energy Laboratory, Golden, CO. Interviewer: Maureen McIntyre.

Deru, M. (29 November 2010). Interview. National Renewable Energy Laboratory, Golden, CO. Interviewer: Maureen McIntyre.

DOE. (2010a). Commercial Building Energy Alliances website. www.buildings.energy.gov/ alliances/.

DOE. (2010b). Commercial Building Partnerships website. www.commercialbuildings.energy.gov/ building_partnerships.html.

DOE. (2010c). EnergyPlus website. www.energyplus.gov.

DOE. (2010d). Commercially Available LED Product Evaluation and Reporting (CALiPER) website. www.ssl.energy.gov/ caliper.html.

Doebber, I. (24 November 2010). Interview. National Renewable Energy Laboratory, Golden, CO. Interviewer: Maureen McIntyre.

Farish, M. (29 November 2010). Interview. Whole Foods Market, Atlanta, Georgia. Interviewer: Maureen McIntyre.

Fricke, B.A.; Becker, B.R. (2010). “Doored Display Cases: They Save Energy, Don't Lose Sales.” ASHRAE Journal (52:9); pp. 18-26.

Hussman (2010). Night Curtain Information.ppt. Slide 3 of 7 (manufacturer's data). Unpublished.

Lawrence Berkeley National Laboratory (LBL). (2010). Radiance website. http: / / radsite.lbl.gov / radiance/.

Leach, M.; Hale, E.; Hirsch, A.; Torcellini, P. (2009). Grocery Store 50\% Energy Savings Technical Support Document. NREL/TP-550-46101. Golden, CO: National Renewable Energy Laboratory. Available at www.nrel.gov/docs/fy09osti/46101.pdf.

Loftus, K. (24 November 2010). Interview. Whole Foods Market, Boston, Massachusetts. Interviewer: Maureen McIntyre.

Scheib, J. 2010. (24 November 2010). Interview. National Renewable Energy Laboratory, Golden, CO. Interviewer: Maureen McIntyre. 


\section{ACRONYMS}

$\begin{array}{ll}\text { AHU } & \text { air-handling unit } \\ \text { ANSI } & \text { American National Standards Institute } \\ \text { ASHRAE } & \text { American Society of Heating, Refrigerating and Air-Conditioning Engineers } \\ \text { CBP } & \text { Commercial Building Partnerships } \\ \text { DOE } & \text { U.S. Department of Energy } \\ \text { EUI } & \text { energy use intensity } \\ \text { HVAC } & \text { heating, ventilation, and air conditioning } \\ \text { IESNA } & \text { Illuminating Engineering Society of North America } \\ \text { NREL } & \text { National Renewable Energy Laboratory } \\ \text { RTU } & \text { rooftop unit } \\ \text { SFA } & \text { skylight to floor area } \\ \text { SHGC } & \text { solar heat gain coefficient } \\ \text { SPOT } & \text { Sensor Placement }+ \text { Optimization Tool } \\ \text { TSD } & \text { technical support document } \\ \text { VLT } & \text { visible light transmittance } \\ \text { WWR } & \text { window-to-wall ratio }\end{array}$

\section{GLOSSARY}

commissioning. Derived from shipbuilding, building commissioning refers to an intensive quality assurance process that begins during design and continues through construction, occupancy, and operations. Commissioning ensures that the new building operates as designed, and that building employees are prepared to operate and maintain its systems and equipment.

condenser. The part of a refrigeration system in which the refrigerant is cooled, changing it from a gas into a liquid, and its heat is discharged to the environment.

core and shell. The basic building-wide elements such as structure, envelope, and the HVAC system. The makeup of the core and shell can vary among projects.

energy use intensity. A unit of measurement that describes a building's energy use. To calculate EUI, divide the total energy consumed in one year, measured in $\mathrm{kBtu}$, by the total floorspace of the building.

EnergyPlus. A whole building energy simulation program developed by the U.S. Department of Energy and used to model energy use in buildings. See www.energyplus.gov for more information. 
evaporator. The part of a refrigeration system in which the refrigerant absorbs heat and changes from a liquid to a gas.

latent cooling load. Cooling load that results when moisture in the air changes from a vapor to a liquid (condenses), releasing heat. The latent load puts additional demand on cooling systems in hot-humid climates.

lighting power density. A measure of electrical power used to provide lighting to a space, expressed in watts per square foot.

living specification. Set of flexible requirements designed to accommodate new products, processes, and more advanced requirements.

Radiance. A suite of programs for the analysis and visualization of lighting in design. See http:/ / radsite.lbl.gov/ radiance/ for more information.

solar heat gain coefficient. The fraction of incident solar radiation admitted through a window, expressed as a number between 0 and 1 . The lower a window's solar heat gain coefficient, the less solar heat it transmits.

SPOT (Sensor Placement + Optimization Tool). Software developed with public funding by Architectural Energy Corporation that assists designers in quantifying the existing or intended electric lighting and annual daylighting characteristics of a space and helps establish the optimal photosensor placement for the space relative to annual performance and annual energy savings. See www.archenergy.com/SPOT/index.html for more information.

visible light transmittance. The amount of visible light transmitted through glazing, which theoretically varies between 0 and 1, although most values among double- and triple-pane windows are between 0.30 and 0.70 . The higher the VLT, the more light transmitted.

whole building. A method of siting, designing, equipment and material selection, financing, construction, and long-term operation that takes into account the complex nature of buildings and user requirements and treats the overall building as an integrated system of interacting components. 
National Renewable Energy Laboratory

1617 Cole Boulevard, Golden, Colorado 80401

303-275-3000 • www.nrel.gov

NREL is a national laboratory of the U.S. Department of Energy Office of Energy Efficiency and Renewable Energy Operated by the Alliance for Sustainable Energy, LLC

NREL/TP-5500-50056・April 2011 